\title{
«Tecnología, pero ¿dónde?»: Decisiones y concepciones de los docentes en relación con el uso de las tecnologías digitales en el aula ${ }^{1}$
}

\author{
«Technology, but where?»: Teachers' conceptions and \\ decision making regarding the use of technology in \\ the classroom
}

\begin{tabular}{c} 
Enna Carvajal \\
\hline $\begin{array}{c}\text { Laboratorio de Innovación en Tecnología Educativa, A.C. } \\
\text { enna_carvajal@yahoo.com }\end{array}$
\end{tabular}

Recibido: 06-7-2014

Aprobado: 02-9-2014

1 El presente estudio fue financiado a través del convenio de asignación de recursos 204718 del Consejo de Ciencia y Tecnología (Conacyt), y fue realizado en colaboración con la Mtra. Deyanira Monroy Zariñan y la Dra. Teresa Rojano Ceballos. 


\title{
Resumen
}

La integración de las tecnologías digitales en la enseñanza enfrenta a los profesores con dificultades para concretar el potencial transformador de las prácticas educativas que se les atribuye. Este trabajo describe y presenta los resultados de un caso de estudio en relación con los procesos de apropiación de recursos digitales para la enseñanza de Geografía en una secundaria de la Ciudad de México. El estudio se propuso analizar las decisiones que el docente toma respecto al uso de la tecnología en su práctica de enseñanza, y explorar sus concepciones sobre cómo llevar a cabo las situaciones de enseñanza con tecnología en el aula y cómo abordar los obstáculos institucionales y técnicos. La investigación es de corte cualitativo; para la recopilación de datos y su análisis, se adoptó una perspectiva micro-etnográfica utilizada para estudiar pequeñas unidades sociales y las interacciones específicas.

Palabras clave: educación secundaria, enseñanza asistida por ordenador, formación en horas de trabajo, estrategias de enseñanza

\begin{abstract}
The incorporation of digital technologies into classroom practice confronts teachers with difficulties to carry out the idea that digital tool's affordances are able to transform learning outcomes and teaching practice. This paper describes and presents data of a case study of one teacher's process for incorporating technology into his geography class in a Mexican secondary school, his participation in a workshop whose purpose was to explore different digital tools and to develop ways of embedding these tools into the design of learning situations. The study aimed to analyze the teacher's decision making process regarding the use of technology for teaching and explore his ideas about how to design learning activities and cope with institutional and technical constraints. This is a qualitative research; a microethnographic perspective, that allows to examine small social units and specific interaction, was used for data collection and analysis.
\end{abstract}

Keywords: Secondary school, computer assisted instruction, inservice training, teaching strategies 


\section{“Tecnología, pero ¿dónde?”: decisiones y concepciones de los docentes en relación con el uso de las tecnologías digitales en el aula}

\section{Introducción}

Durante los últimos años en México, se han implementado diversos programas orientados a la incorporación de las tecnologías digitales en aulas de educación básica, tales como Enciclomedia, Habilidades Digitales para Todos (HDT); y, en la actualidad, el programa de dotación de equipos de cómputo portátiles y tabletas denominado micompu.mx. Los modelos de uso de la tecnología que se proponen son variados: unos enfatizan la enseñanza mediante el despliegue de materiales interactivos en pantallas instaladas en el salón de clase, otros se centran en las actividades diseñadas para el aprendizaje de los alumnos que trabajan en aula de medios con distintas formas de organización; algunos más intentan promover la autogestión del aprendizaje y el trabajo colaborativo a través del uso de dispositivos personales.

Desafortunadamente, como en otras regiones, las grandes inversiones en infraestructura -por lo general- no han sido acompañadas de un diagnóstico completo de las condiciones de infraestructura y un análisis de la viabilidad de los proyectos. De la misma manera, si bien la política educativa actual hace énfasis en el fortalecimiento de los Consejos Técnicos Escolares como una estrategia que contribuye a «impulsar la capacitación permanente de los docentes para mejorar la comprensión del modelo educativo, las prácticas pedagógicas y el manejo de las tecnologías de la información con fines educativos» ${ }^{2}$ (Diario Oficial de la Federación 2013), lo cierto es que las inversiones en el diseño y puesta en marcha de programas de formación docente en el uso de la tecnología no han sido equivalentes a las realizadas en la infraestructura (Area Moreira, 2011; Bingimlas, 2009; Kalman y Guerrero, 2013; Pelgrum, 2001).

En la última década, la Secretaría de Educación Pública en México ha destinado 3 mil millones de dólares a la compra de equipo de cómputo, mientras que los recursos para el programa de formación continua y capacitación para el profesorado alcanzaron solo los 250 millones de dólares. Asimismo, del total de la oferta de formación para los docentes, solo el 13\% aborda el uso de la tecnología en el aula (Gómez Morín ${ }^{3}$, citado por Del Valle, 2014) con énfasis en la certificación en el conocimiento de software comercial como el procesador de textos, la hoja de cálculo y las herramientas de presentación.

De la misma manera, existe poca evidencia de que la presencia de las computadoras y otras tecnologías digitales, en sí misma, haya mejorado el apren-

2 Corresponde al Apartado VI.3 México con Educación de Calidad, Estrategia 3.1.1., presente en el Plan Nacional de Desarrollo 2013-2018.

3 Lorenzo Gómez Morín es investigador de Flacso y Subsecretario de Educación Básica de la Secretaría de Educación Pública para el período 2000-2006. 
dizaje y la enseñanza en el sistema escolar (Area Moreira, 2011; Cuban, Kirkpatrick y Peck, 2001; Hennesy, Ruthven, y Brindley, 2005; Pelgrum, 2001). Los estudios recientes sobre los efectos de los ambiciosos programas de dotación de equipos de cómputo personales sobre los puntajes en exámenes y otras medidas de logro académico no son concluyentes (Severin y Capota, 2011; Valiente, 2010). Las variadas condiciones de implementación y de evaluación de los programas dificultan la generalización de resultados. Asimismo, se ha señalado (Warschauer, 2006) que los exámenes estandarizados no están diseñados para apreciar los aprendizajes promovidos por el uso de las tecnologías digitales.

La comprensión sobre el proceso de innovación tecnológica en la práctica pedagógica es aún incipiente y remite a diversos factores que interactúan de manera compleja: además de las creencias y actitudes de los docentes, se consideran sus habilidades y su confianza en el uso de la tecnología, el contexto social y organizacional. Todos ellos son de importancia central para entender el proceso de apropiación pedagógica (Coll et ál., 2008; Hennesy et ál., 2005; Kalman y Guerrero, 2013; Somekh, 2008; Sutherland et ál., 2004). Los estudios que documentan experiencias de apropiación dan cuenta de que, en todos los casos, los profesores tuvieron la oportunidad de intercambio con colegas e investigadores para explorar soluciones a través de un período extendido de tiempo.

El presente estudio forma parte del esfuerzo que el Laboratorio de Innovación en Tecnología Educativa, LITE, ${ }^{4}$ ha emprendido para la exploración de los usos efectivos que profesores y alumnos hacen de las tecnologías digitales. Para ello, se sigue la línea de que es en las actividades que llevan a cabo, mediadas por las posibilidades de comunicación e intercambio que ofrecen, donde hay que buscar las claves para comprender y valorar su impacto en la educación.

\section{Antecedentes y propósitos}

La experiencia que a continuación se describe forma parte de un estudio más amplio que se propuso explorar cómo los profesores de secundaria se apropian y usan recursos tecnológicos digitales, a partir de su participación en sesiones semanales de trabajo en un taller entre julio y diciembre de 2013. Ello se realizó con el fin de que conocieran y exploraran diversos materiales y herramientas digitales, e hicieran una selección para construir sus propias situaciones de aprendizaje. En este proceso, una investigadora del Laboratorio asesoró y acompañó ${ }^{5}$ a cuatro profesores de distintos planteles y modalidades

4 El LITE es una asociación civil integrada por un grupo de académicos y desarrolladores de herramientas digitales para apoyar la enseñanza y el aprendizaje en distintos contextos y proyectos educativos. El laboratorio hace énfasis en el desarrollo de contenidos digitales educativos públicos y gratuitos, así como en la investigación de los usos y estrategias de apropiación de dichos recursos en el sistema escolar.

92 I 5 Se entiende el acompañamiento como la orientación, el intercambio y la exploración de insumos para que los docentes construyan estrategias a partir de sus ideas respecto 
de la educación secundaria en la Ciudad de México. Para la investigación, se registraron estas sesiones de trabajo, se entrevistó a los profesores y se observaron las sesiones de clase con sus alumnos para estudiar el uso que daban a los recursos tecnológicos para la enseñanza. Durante el semestre que duró la experiencia, los maestros diseñaron cartas descriptivas, así como materiales y hojas de trabajo para proponer a sus estudiantes la utilización de los recursos digitales de su elección.

Para este artículo, se integró el estudio de caso de uno de los profesores, quien imparte la asignatura de "Geografía de México y el mundo» en una secundaria para trabajadores de la Ciudad de México. Los propósitos del estudio son los siguientes:

a) Analizar las decisiones que el profesor toma en relación con el uso de la tecnología en la enseñanza

b) Conocer sus concepciones sobre cómo implementar las situaciones de enseñanza con tecnología en el salón de clases y explorar su experiencia con esta en la práctica en el aula

\section{Marco de referencia}

Los usos de la tecnología en situación escolar están sujetos a tensiones entre la herramienta tecnológica y el uso que se le da en un contexto particular, como señalan varios estudios (Coll Mauri, y Onrubia, 2008; Hennesy et ál., 2005; Kalman y Guerrero, 2013; Rojano, 2006; Somekh, 2008). El lugar que ocupa la tecnología en el aula representa la manera en que el uso se inserta en un ambiente y cómo converge con las prácticas preexistentes, independientemente de lo que los desarrolladores y los diseñadores de la política educativa conciben sobre cómo deben ser utilizadas las herramientas digitales por los profesores y estudiantes.

Uno de los problemas más claramente identificados en la implementación del uso de tecnología en el aula tiene relación con los acercamientos pedagógicos centrados en el profesor. Las evidencias indican que los cambios en las prácticas de enseñanza suceden lentamente. Además, requieren de una práctica informada de parte de los maestros y de la valoración de los factores contextuales y situacionales que influyen, y pueden ser determinantes en la forma como se incorpora el uso de la tecnología a la enseñanza (Area Moreira, 2011; Assude, Buteau y Forgas, 2010; Cuban et ál., 2001; Hennesy et ál., 2005; Kalman y Guerrero, 2012; Pelgrum, 2001).

En el sistema mexicano de enseñanza secundaria, se cuenta con ejemplos de proyectos que han intentado llevar la tecnología a las aulas (Carvajal, 2011; Rojano, 2006) a partir de una fundamentación en la investigación respecto a

al de la tecnología en su práctica educativa, en un contexto de colaboración entre especialistas y colegas. 
las potencialidades de entornos tecnológicos de aprendizaje específicos. Sin embargo, la implementación de dichos proyectos ha demostrado, por un lado, que la responsabilidad de la enseñanza no debe recaer en la introducción de la tecnología; y, por otro, que una de las partes más débiles es la falta de un trabajo previo y continuo con los profesores responsables del uso de las herramientas. Estas experiencias reconocen que no hay maneras claras y directas de introducir la tecnología al salón de clases para mejorar el aprendizaje. Por el contrario, involucran tomar el riesgo de experimentar e imaginar las potencialidades de tecnologías particulares en contextos en los que el aprendizaje tendrá lugar, dadas las condiciones al alcance de los participantes. El foco de interés de este estudio es el trabajo del docente, cómo se apropia de las herramientas tecnológicas y reflexiona sobre la mejor manera de introducirlas en el aula. Con el fin de apoyar el análisis, se han seleccionado dos herramientas teóricas que a continuación se detallan.

\subsection{Iniciativa de diseño por asignatura y acercamiento instrumental}

Tanto los postulados del diseño por asignatura como del acercamiento instrumental sirvieron como base para el logro de los propósitos trazados, como se señala enseguida. Para abordar el propósito I -es decir, las decisiones que el profesor toma en relación con el uso de la tecnología-, se utilizaron los siguientes ejes básicos, inspirados en the subject initiative design [iniciativa de diseño por asignatura], empleada en el proyecto InterActive de la Universidad de Bristol entre los años 2004 y 2007 (Sutherland, Robertson y John, 2009):

Tabla I. Ejes básicos de análisis del propósito I

Ejes básicos de análisis

1) Decisión de enfocarse en un área específica del currículo

2) Decisión de utilizar una o varias herramientas tecnológicas (hardware y software) disponibles en la escuela y si se explicita la relación entre la herramienta elegida y la especificidad del contenido.

3) Decisión de buscar ayuda especializada o de recurrir a compañeros docentes con experiencia en la utilización de tecnología en clase

4) Decisión sobre cómo diseñar la actividad con tecnología para que los alumnos se involucren en realizarla, y si considera la experiencia que los alumnos han tenido con la tecnología dentro y fuera de la escuela

5) Decisión de afrontar las dificultades para el uso de la tecnología en la escuela, provenientes de limitantes y restricciones institucionales, maneras de hacer frente a dificultades particulares, como - por ejemplo- problemas de horario, de conexión con el currículo, presión para cubrir el programa de estudios de su asignatura, o acceso limitado a la tecnología disponible.

Fuente: Propuesta del proyecto InterActive. Sutherland, Robertson y John, 2009. 
Los cuatro primeros pueden considerarse vinculados al diseño de la actividad didáctica mientras que el quinto tiene relación con la implementación. Los ejes sirvieron de base tanto para el diseño de los instrumentos de recolección de datos (guía de observación y de entrevista), como para la elaboración del marco de análisis de estos.

En el caso del propósito II -las concepciones que el profesor tiene sobre cómo llevar al aula las situaciones de enseñanza con tecnología que diseñóse recurrió a elementos teóricos del acercamiento instrumental desarrollado por Vérillon y Rabardel (1995), que permiten profundizar en el análisis de las concepciones del profesor. Esta aproximación hace posible explorar la problemática del papel del docente en los procesos de asimilación de la tecnología en la escuela, considerando variables intrínsecas a la enseñanza y el aprendizaje en un entorno tecnológico, y variables contextuales y situacionales que pueden ser determinantes en tales procesos.

La idea central en el acercamiento instrumental consiste en considerar que un instrumento es una entidad que combina un objeto (material o simbólico) con esquemas que organizan las acciones del sujeto. El proceso de construcción de estos esquemas es a lo que se llama "génesis instrumental» y tiene lugar en dos niveles: instrumentalización (el proceso está orientado al uso del objeto o artefacto) e instrumentación (el proceso se enfoca en la realización de la tarea). Un ejemplo de esta diferencia entre ambos niveles se observa cuando los alumnos tienen que aprender a «arrastrar» puntos en la pantalla en un programa de geometría dinámica (proceso de instrumentalización) y cuando aprenden a «arrastrar» puntos, por sí mismos, con una intención matemática, no solo animados por los objetos en movimiento (proceso de instrumentación).

La idea de integración instrumental (Assude et ál., 2010) se propone como un medio para describir cómo el profesor organiza las condiciones para la génesis instrumental de la tecnología presentada a los estudiantes, y hasta qué punto su intervención propicia el aprendizaje. A la integración instrumental subyacen dos características de la situación de enseñanza: el conocimiento de los alumnos respecto al artefacto o herramienta, y el propósito didáctico de las tareas que les son presentadas. De la combinación de estas dos características, se derivan cuatro modos de integración tecnológica en la enseñanza, en un orden de menor a mayor nivel de integración instrumental: iniciación, exploración, reforzamiento y simbiosis.

a) Iniciación instrumental: El profesor se propone que los alumnos aprendan a usar la tecnología (el artefacto). En esta etapa, el contenido de la asignatura es mínimo; y, por lo tanto, también lo es la integración instrumental.

b) Exploración instrumental: El profesor se propone mejorar tanto el conocimiento del artefacto o herramienta como el conocimiento del contenido de la asignatura. Los alumnos exploran la tecnología a través de tareas de 
contenido. El maestro puede dar información sobre el uso del artefacto y hacer explícitos algunos vínculos con el contenido.

c) Reforzamiento instrumental: Los alumnos enfrentan dificultades instrumentales mientras realizan una tarea de contenido. El profesor les proporciona información acerca del uso específico de algún comando del artefacto para remontar la dificultad técnica, pero el objetivo del profesor es mejorar el conocimiento de los alumnos respecto al contenido.

d) Simbiosis instrumental: Los alumnos realizan tareas de contenido que les permiten mejorar tanto su uso del artefacto o herramienta como su conocimiento del contenido, porque ambos están fuertemente interconectados. La integración instrumental es máxima.

Estos modos de integración pueden ser utilizados metodológicamente para comparar los diseños planeados y su realización en el salón de clases. En este estudio, los modos de integración sirvieron para indagar la manera en que los docentes conciben la transferencia del uso de la tecnología de su experiencia personal con ella, a la práctica en el aula.

\section{Diseño metodológico}

En el estudio, se asume que los efectos en las prácticas de uso de la tecnología solo pueden ser analizados en función de su relación con el contexto específico, las prácticas sociales y los discursos en los cuales la tecnología es utilizada. En este caso, se optó por una perspectiva microetnográfica ${ }^{6}$ (Gee y Green, 1998, p. 131) la cual permite comprender la construcción social del contexto: los significados vertidos y/o construidos en el proceso por los participantes, y las diferentes formas de participación, con énfasis en las interacciones específicas en torno al uso de la tecnología.

Con el fin de observar en situación y acercarse al detalle de la apropiación y las prácticas de uso de las herramientas digitales, se utilizaron diferentes técnicas de recolección de datos. El corpus de datos estuvo integrado por dos entrevistas realizadas al profesor - una durante la mitad de la experiencia, y otra al final-, transcripciones de las cuatro sesiones del taller audiograbadas, y tres sesiones de clase con un grupo de primer grado. Este corpus fue contextualizado con otras fuentes de información obtenidas en el trabajo de campo, como las bitácoras de la tutora, los documentos generados por el profesor (planes de clase y rúbricas), los productos de los estudiantes

6 La microetnografía ha sido utilizada para estudiar pequeñas unidades sociales en las que la atención se centra en un tipo particular de interacción o fenómeno claramente definido, en escenarios específicos. En este caso, proporciona una forma de analizar lo que los maestros y estudiantes hacen y dicen, las influencias recíprocas de sus acciones; y, en este sentido, la construcción conjunta del contexto en el cual la interacción tiene lugar. 
y las videograbaciones de las interacciones de estos con la computadora durante la realización de la tarea asignada. Para el análisis, se partió del modelo interactivo de Miles y Huberman (1994), es decir, la recolección de datos con triangulación, condensación de los mismos, codificación y categorización, elaboración y verificación de conclusiones. Para condensar los datos, se atendió al énfasis de la investigación en la toma de decisiones de los profesores en cuanto al uso de la tecnología y sus ideas sobre cómo transferir sus diseños y propuestas al trabajo en el aula. $\mathrm{Al}$ respecto, se consideraron los ejes definidos ya mencionados.

Con lo anterior en mente, se revisaron las transcripciones y los productos escritos seleccionados. Asimismo, se identificaron episodios temáticos significativos para la investigación. Finalmente, se codificaron las diferentes interacciones verbales o actos de habla de los participantes con descriptores $o$ códigos definidos en concordancia con los temas vinculados a los propósitos de la investigación o con algunos nuevos temas identificados. La construcción de códigos sirvió como una especie de «vocabulario especializado» para dar cuenta de lo observado (Dyson, 1989, p. 21).

Así, se integró una narrativa analítica para ofrecer una descripción organizada del proceso de análisis. En dicha narrativa, se involucró los diferentes eventos o sesiones de trabajo del taller, las clases con estudiantes y las entrevistas con el docente. Ello se llevó a cabo con el fin de documentar ejemplos representativos de los temas recurrentes y significativos para entender las decisiones del docente en relación con el uso de la tecnología. Asimismo, se incorporaron materiales de trabajo y productos realizados tanto por el profesor como por sus estudiantes, para integrar una visión estructurada de la relación entre participación, toma de decisiones, realización de la actividad, y uso de herramientas y recursos a través del intercambio entre el docente, la tutora y los estudiantes. A continuación, se presentan el contexto de la investigación, así como fragmentos de la narrativa del caso del docente de Geografía para el análisis.

\section{Una secundaria para trabajadores}

El maestro Gregorio imparte la asignatura de «Geografía de México y del mundo» en el primer grado de una secundaria para trabajadores en la Ciudad de México, desde hace seis años. Esta modalidad de educación básica ${ }^{7}$ atiende a quienes rebasan la edad establecida para ingresar en escuelas de educación

7 La educación básica secundaria en México tiene una duración de tres años. Las modalidades escolarizadas disponibles para cursar el nivel si se egresa de la primaria con menos de dieciséis años son la secundaria general, la secundaria técnica y la telesecundaria. Para los egresados con más de quince años, existe una opción escolarizada: la secundaria para trabajadores. Además, es posible concluir el nivel en el sistema abierto y en las secundarias comunitarias para localidades rurales con un número muy reducido de habitantes. 
regular. A pesar de denominarse «Escuelas Secundarias para Trabajadores», no es requisito que los aspirantes a ingresar tengan un empleo. Actualmente, se considera a su población en situación de vulnerabilidad: se trata de estudiantes provenientes de otras modalidades educativas que muchas veces han sido rechazados por problemas de conducta y/o aprovechamiento escolar y quedan marginados de dichos espacios. A la fecha, hay 63 secundarias de este tipo en la Ciudad de México; en su mayoría, en turno vespertino y nocturno. Poco menos de la mitad de ellas tienen un plan de estudios que los alumnos cursan en solo tres semestres, en lugar de los tres años de las otras modalidades (Canedo Castro, 2011; Ruiz Muñoz, 2011). Este es el caso de la escuela en la que labora el maestro Gregorio.

La infraestructura tecnológica del plantel incluye tres aulas de medios, equipadas con computadoras de escritorio -dos de ellas con conexión a Internet-; y cuatro aulas Enciclomedia. Las últimas se encuentran equipadas con una computadora de escritorio, una impresora, un proyector y un pizarrón electrónico. Este equipamiento ha sido instalado a raíz del programa homónimo del Gobierno Federal, que dotó de infraestructura tecnológica básica a algunas escuelas secundarias. Dado que el inmueble no pertenece a la secundaria para trabajadores - pues normalmente comparten edificio con secundarias generales diurnas y/o primarias-, sus estudiantes no tienen acceso a dicha infraestructura. Se debe considerar que compartir espacios con otras modalidades o niveles es usual tras la significativa baja de matrícula de la modalidad en los últimos años (Ruiz Muñoz, 2011). A pesar del equipamiento, el maestro se ve obligado a llevar su computadora personal, un proyector e incluso las cortinas para oscurecer el aula en la cual imparte sus clases.

La asistencia promedio a las clases de Geografía en el primer grado de secundaria es de quince alumnos, aunque no todos asisten a diario. Esta es una situación común desde que la modalidad se volvió una alternativa para estudiantes «rechazados» de otras modalidades: se presenta un alto índice de deserción (50\%) y de tránsito de una escuela a otra (Canedo Castro, 2011). Además, los estudiantes no siempre concluyen sus estudios (Ruiz Muñoz, 2011).

Este profesor es un usuario frecuente de la tecnología a la que se ha acercado de manera autodidacta principalmente. En su paso por el bachillerato tecnológico -donde laboró siete años-, aprovechó la experiencia de colegas que impartían computación para aprender el uso de diversas herramientas y programas (Flash, Movie Maker, Publisher, PowerPoint y Excel son algunas de las que menciona), que ha utilizado para el diseño de actividades con sus estudiantes. Estos intercambios entre colegas se llevaban a cabo por iniciativa de ellos mismos, y no tenían valor curricular para el sistema de formación docente oficial. Ninguno de los cursos de formación que el sistema de educación le ha proporcionado ha abordado el uso de la tecnología para la enseñanza. El uso frecuente que da a la tecnología en el aula es la proyección de videos e imágenes que selecciona de sitios en Internet -como YouTube-, para apoyar el desarrollo 
de sus clases. Debido a las limitaciones de infraestructura ya comentadas, el profesor utiliza su computadora y proyector en estos casos.

\section{5. “Tecnología, pero ¿dónde?”}

A continuación, con el fin de dar cuenta de las decisiones del maestro respecto al uso de la tecnología y acercarse a sus concepciones sobre cómo implementar las situaciones didácticas que diseñó en el aula, se intercalarán fragmentos de tres situaciones: a) la participación del docente en el taller de apropiación de herramientas digitales con una tutora del Laboratorio, b) las sesiones de trabajo en la computadora con uno de los equipos de estudiantes, y c) las entrevistas realizadas a la mitad y al final de la experiencia. Por razones de espacio, solo se incorporan algunos fragmentos que resultaron significativos para el análisis.

\subsection{Decisiones en relación con el diseño de la actividad}

Durante el taller, el profesor Gregorio tuvo la oportunidad de conocer y explorar diferentes recursos educativos digitales disponibles en el repositorio del Laboratorio: desde interactivos de uso específico, hasta herramientas para el despliegue de contenidos que incorporan recursos tecnológicos incrustados de manera dinámica, así como una herramienta para la construcción de diálogos inteligentes. Si bien se mostró interesado en ellas, decidió trabajar con el programa Movie Maker para que los estudiantes produjeran un video relacionado con temas revisados en clase. Definió el tipo de actividad a realizar con sus alumnos, los temas que podrían abordarse en el video, la forma de organización del trabajo y los materiales que utilizarían para elaborarlo. A partir de esta decisión, el maestro trabajó un viernes cada quince días con un grupo de primer grado. Estas clases se impartieron en paralelo a las sesiones del taller, de manera que la tutora acompañó al profesor durante todo el proceso.

Como parte de la planeación de la actividad, el maestro instaló en dos laptops ${ }^{8}$, algunas fotografías de maquetas que los estudiantes elaboraron durante el curso, así como archivos con música y efectos de sonido como insu-

El Laboratorio prestó dos computadoras personales (laptop) para el trabajo con los estudiantes. Las actividades realizadas por dos equipos, de siete alumnos aproximadamente cada uno, fueron grabadas con el software Camtasia en tres ocasiones. Camtasia es un programa de captura de pantalla que permite el registro de la actividad realizada en las pantallas de una o un grupo de computadoras, permitiendo la observación de los procesos de manera no invasiva. No fue posible registrar las sesiones subsecuentes, pues la versión libre de Movie Maker falló y el profesor y la tutora decidieron utilizar Camtasia para la producción del video: en este caso, el programa no permite realizar dos grabaciones distintas de manera simultánea y se privilegió el trabajo de los estudiantes. 
mos para realizar los videos. También, creó una estructura de carpetas para cada uno de los dos grupos, de modo que los estudiantes pudieran guardar los productos que iban generando. Asimismo, diseñó y entregó a los alumnos una rúbrica de evaluación y los roles que los miembros del equipo habrían de desempeñar en el desarrollo del proyecto.

Para facilitar el análisis, se resumen las actividades realizadas en las tres sesiones de trabajo registradas con los estudiantes:

a) En la primera sesión, el profesor dio a los alumnos las instrucciones generales para explorar el software Movie Maker, y propuso que cada uno de los miembros del equipo manipulara el programa y ejecutara diversos procedimientos. Asimismo, se hicieron pruebas para crear títulos y grabar audios, y se exploraron las funciones para crear efectos y transiciones en un video.

b) Durante la segunda sesión, el profesor precisó las instrucciones sobre la metodología de trabajo: explicó el llenado de la rúbrica para la evaluación y las tarjetas con los roles de los miembros del equipo definidos para apoyar en la organización del trabajo. También, presentó las carpetas que creó para guardar los avances en el trabajo que contenían los insumos para su elaboración. Abordó los posibles temas para el video. Hubo una primera aproximación a la organización del trabajo entre los alumnos: hablaron sobre la selección del tema, discutieron la división de los roles, llenaron su primera rúbrica.

c) La tercera sesión de trabajo giró alrededor de la interacción entre los alumnos de uno de los equipos de trabajo. El profesor les recordó la tarea que debían realizar. Los alumnos emplearon el tiempo restante en la manipulación de la herramienta y trataron de ponerse de acuerdo en el contenido del trabajo a partir de la selección de imágenes.

La selección de la actividad estaba relacionada con la intención del profesor de que sus estudiantes utilizaran la tecnología para expresarse. En la entrevista, refirió que su interés principal no tenía que ver con los recursos tecnológicos -algunos de los cuales consideró demasiados simples-, sino con que los estudiantes tuvieran oportunidades para interpretar y analizar la información. Ello coloca a la tecnología en un nivel de subordinación ante la necesidad pedagógica.

[...] hay cosas que se me hacen como muy burdas para presentarlas a los muchachos [...] ponerles por ejemplo unos monitos que apenas y se van moviendo en el video, eso no me funciona en el salón de clases con los chavos. Si yo, por ejemplo, les llevo un video donde se presente una temática real, y ellos por ejemplo revisando causas y efectos de la situación que se está presentando, eso nos da un impacto. Trabajo eso como en primer plano para reforzar la reflexión y la crítica, y 
lógicamente el análisis que vamos a desarrollar al interior del salón de clases. A nosotros nos dicen que los muchachos que tenemos la verdad es que no generan ese análisis; yo, la verdad, les digo que sí.

El maestro es cuidadoso al diseñar la actividad, especialmente, en relación con la organización y aspectos formales. Se entiende que, como usuario frecuente de la tecnología, selecciona una herramienta de trabajo que ya ha utilizado en otras ocasiones (Movie Maker) y que conoce con cierto detalle. Se concentra, entonces, en los elementos que pueden dar estructura a la situación didáctica que quiere promover: aprovecha las maquetas elaboradas por sus alumnos (figura II); define el alcance para dar cumplimiento a la revisión de los conceptos curriculares, y elabora materiales para organizar el trabajo por equipo -como la definición de roles para cada uno de sus integrantes- (figura I). Asimismo, establece una rúbrica de evaluación que los estudiantes deberán llenar al finalizar cada sesión de trabajo (figura III).

Figura I. Definición de roles

\begin{tabular}{|c|c|}
\hline 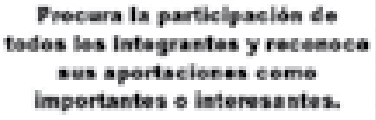 & 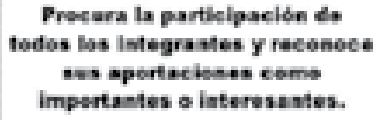 \\
\hline 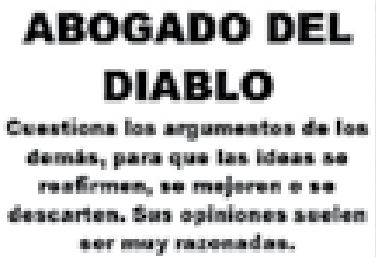 & 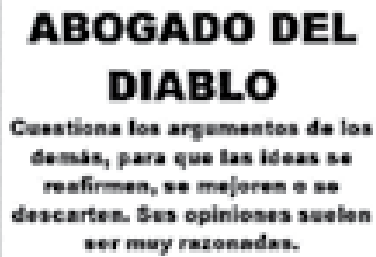 \\
\hline $\begin{array}{c}\text { SUPERVISOR } \\
\text { Atlende ses tedes les nolembres } \\
\text { det equipo entes eatendiende of } \\
\text { tems. Se detiene para actarar } \\
\text { dedas. }\end{array}$ & 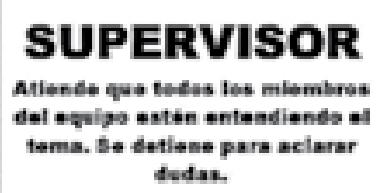 \\
\hline
\end{tabular}


Figura II. Maqueta de los estudiantes

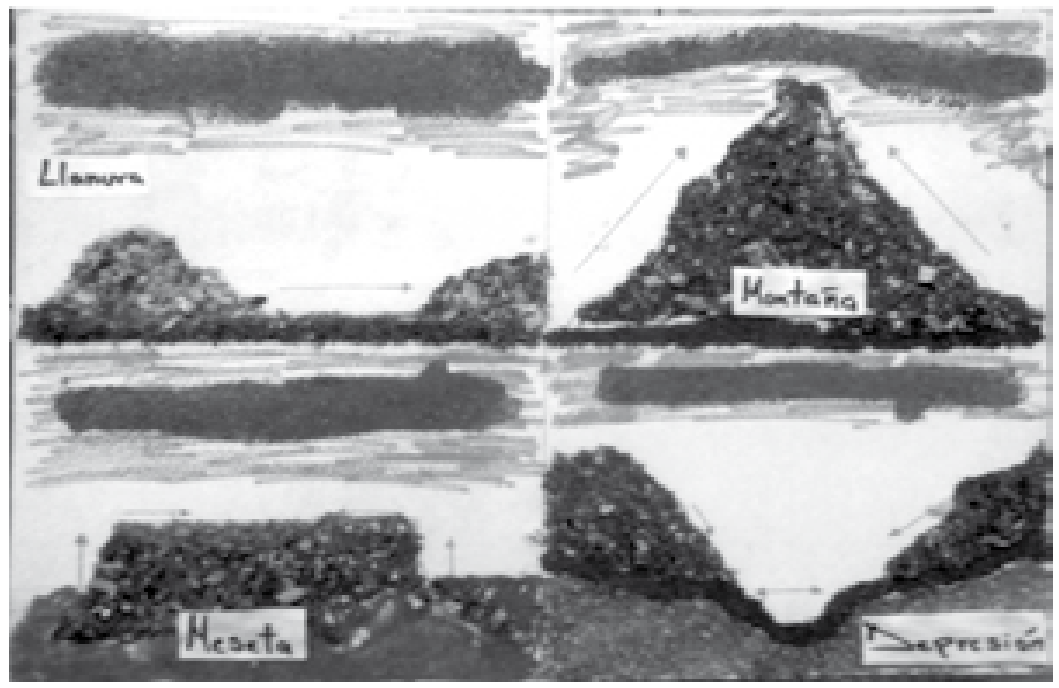

Figura III. Rúbrica para la evaluación

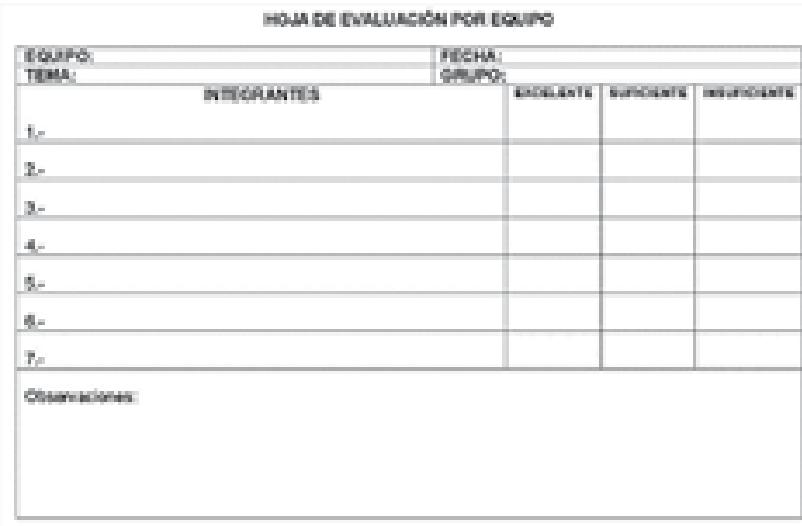

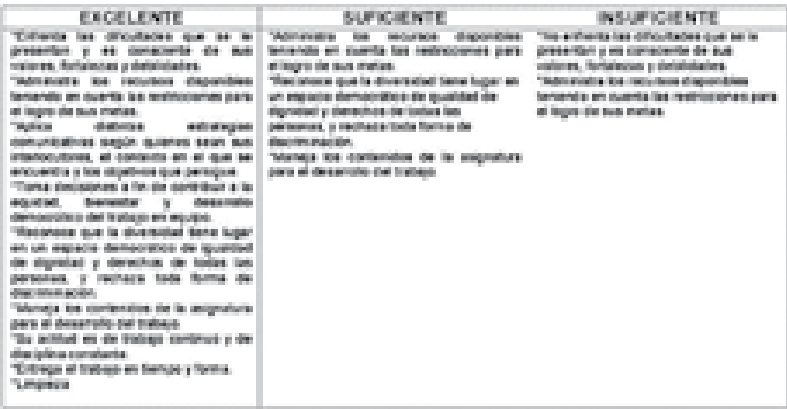


En esa rúbrica, se proponen criterios generales que no hacen énfasis especial en el uso de la tecnología. El profesor concibe la actividad como una pieza completa conformada por varias partes. En ese sentido, propone una rúbrica que apoya en la evaluación no solo del trabajo con los contenidos, sino también del manejo de todos los recursos disponibles, y del tipo de actividad y las actitudes que los estudiantes despliegan para apoyar la colaboración en el equipo.

Para organizar el trabajo en el aula, el profesor tiene planeado que los estudiantes exploren el programa durante una sesión, manipulando las funciones y realizando operaciones con el material que utilizarán en la elaboración del video, disponible en las computadoras preparadas por el mismo. Las siguientes sesiones se dedicarían a elegir el tema, ubicar los contenidos e imágenes, y grabar el video.

\subsection{Decisiones para afrontar las dificultades}

Dada la precariedad de las situaciones escolares, el profesor tuvo que modificar algunos aspectos de su planeación original. El maestro enumeró obstáculos, como la falta de tiempo y el acceso a los equipos de cómputo, durante una de las sesiones del taller:

Lo que pasa es que, maestra, a veces uno quiere hacer muchas cosas con los chavos, pero en realidad, el tiempo -sobre todo, el tiempo- y el material que podemos utilizar. No es lo mismo trabajar con una máquina con quince alumnos, trabajar de manera individual con una máquina; ahí es de una forma distinta. A lo mejor en este momento, el proyecto lo pensaría como un ejercicio.

De la misma manera, en la entrevista, se refirió a la paradoja que resulta del continuo exhorto que se hace a los maestros para utilizar recursos tecnológicos cuando las condiciones de acceso son tan limitadas:

Muchas ocasiones nos mandan a los cursos de actualización docente en donde nos dicen: «Es que el docente tiene que trabajar con tecnología», tecnología, tecnología, pero ¿dónde? Si en la escuela no nos permiten ni utilizar una máquina, ni una computadora; digo, están las computadoras, pero no las podemos utilizar. Entonces, eso de alguna manera a nosotros también nos limita. Y, por ejemplo, a la secundaria llevo mi lap, llevo las bocinas, llevo el cañón, llevo la extensión, llevo las cortinas [... $]^{9}$

Las carencias materiales, tanto de la escuela como de los estudiantes, y el breve tiempo para realizar el proyecto orillaron al profesor a proporcionar los 
insumos. Asimismo, dado que los estudiantes no estaban familiarizados con el programa que iban a utilizar, el profesor planteó la estrategia de trabajar los contenidos de manera simultánea a la exploración del programa para conocer su operación. Sin embargo, cambió de estrategia, tanto por el tiempo y el escaso avance de los estudiantes, como por los problemas técnicos que se fueron presentando, como se aprecia en el siguiente diálogo con uno de sus estudiantes.

M: Vale, OK. Y, en escritorio, tengo una carpeta que dice «Geografía», ¿ya la ubicaron?

A: Sí.

(En el Explorador de archivos, seleccionan la opción de «Escritorio»y aparecen en la ventana las carpetas y archivos que hay en esa ubicación. Siguen las indicaciones del maestro y ubican la carpeta «Geografía»).

M: OK, ¿ya ubicaron la carpeta de Geografía?

A: Sí.

M: OK, chavos, los videos, las imágenes que vamos a utilizar van a estar en una carpeta ya integradas en el espacio de escritorio. Ahí, va a estar nuestra carpeta de Geografía.

En este intercambio, el maestro indica a sus estudiantes en qué carpeta podrán encontrar los insumos para la elaboración del video. Por el momento, aprendieron la navegación para ubicar una carpeta «vacía», pues el profesor no tuvo tiempo para colocar toda la información e imágenes que había recopilado.

Durante gran parte de los 45 minutos que dura la sesión de clase, los estudiantes se enfrentaron con dificultades para operar un programa novedoso para ellos. Contrario a lo planeado, el maestro decidió dedicar más tiempo a la exploración de las funciones básicas del programa con los estudiantes y enfrentar los problemas técnicos antes de trabajar con el contenido académico. Ello lo llevó a cabo con el fin de que los estudiantes pudieran familiarizarse con la herramienta, navegar libremente y, posteriormente, se concentraran en los aspectos formales de la tarea.

No obstante, estas situaciones no detuvieron al maestro para emprender un proyecto que presentó algunas dificultades fuera de su control para la ejecución. Por ejemplo, tuvo que familiarizarse con el sistema operativo Windows 8 para orientar a los estudiantes en la navegación. Dicho sistema fue instalado en las laptop que el Laboratorio le facilitó, pero que él nunca había utilizado.

De la misma forma, enfrentó la dificultad que implica para los estudiantes organizarse en equipos, tanto por la rotación como por la inasistencia a clases, la aparente dispersión de los alumnos y la falta de compromiso. El profesor desplegó estrategias como la definición de roles -a manera de apoyo- para 104 I que los jóvenes pudieran realizar actividades más específicas, y flexibilizó la 
selección del tema del video para estimular el interés y la participación de sus estudiantes.

Casi al final del semestre, entre la tutora y el maestro, decidieron migrar a Camtasia para realizar el video, debido a que -tras sucesivas pruebas- Movie Maker presentó una falla que ocasionó la pérdida de parte de la información que los estudiantes habían trabajado. Preocupado por el lento avance de los equipos, decidió realizar una sesión especial en el salón de clases, en la cual solicitó a los alumnos reproducir la línea de temporal del video en sus cuadernos. Para ello, especificó las imágenes que iban a utilizar, el orden en que se colocarían y la narración a grabar para acompañar la transición entre ellas. Estas decisiones indican la flexibilidad con que el maestro ajustó las tareas frente a las limitaciones existentes.

En el siguiente fragmento de la entrevista, el profesor señaló algunas dificultades y demoras que implica la organización del trabajo en equipo, confiando en que al final las estrategias para ahorrar el tiempo y la presión, sirvieran para terminar la actividad.

Lo primero que teníamos que hacer era explicarles cómo trabajar; y, sinceramente, el tiempo también es muy corto: son 45 minutos, y el traslado que hacemos de un lugar a otro nos resta tiempo. Si trabajamos en equipo, la verdad, que es mucho más difícil y el tiempo se acorta mucho más, muchísimo más, porque finalmente estamos hablando de que son chavos que no tienen todavía esa capacidad o habilidad para organizarse de manera rápida, precisa, asertiva; ellos lo que quieren es no hacer nada (ríe) básicamente, sí, pero cuando ellos ya observan la presión que existe en el trabajo, trabajan $[\ldots]$

A partir de la falla del software y la pérdida de información, los alumnos decidieron cambiar de tema y le propusieron al maestro trabajar sobre problemáticas sociales que afectaran a la población, como discriminación, injusticia social, marginación y hambre. Como no contaban con imágenes relacionadas con el tema, el profesor se comprometió a buscar y proporcionar el material. El docente explicó en la entrevista que los jóvenes ya habían abordado el tema en la clase de Geografía, y que -a partir de una presentación en la asignatura de Español- tomaron las ideas para organizar los contenidos. En una conversación posterior, el maestro comentó con la tutora detalles de las decisiones que tomó junto con los equipos para llegar a la versión final del video ${ }^{10}$ :

$\mathrm{Al}$ inicio, ellos querían trabajar regiones naturales. Cuando falla el Movie Maker y nos adentramos a lo que es Camtasia, y como nosotros habíamos trabajado lo que eran las situaciones sociales, económicas y

10 El avance en la elaboración del video de los estudiantes podrá consultarse en la página del proyecto, que no se incluye en la presente versión ciega. 
políticas... bueno, todos esos aspectos en ciertos espacios geográficos dentro de la misma población, ellos me dijeron: «Maestro, ¿podemos cambiarle? Maestro, nosotros vamos a traer la información». Entonces yo, en realidad por la situación, por la condición que tenemos les dije: «No, mejor yo les traigo imágenes». Genero una selección de imágenes, las busco, yo las coloco y ustedes identifican de acuerdo a su temática, y de acuerdo a la información que ustedes están manejando y que están generando, seleccionan y ya las acomodan.

En síntesis, se pueden destacar al menos cuatro puntos relevantes del proceso de la toma de decisiones del docente durante el proyecto:

a) El énfasis en el uso de la tecnología para que los estudiantes tengan oportunidad de elaborar un producto

b) El énfasis en la integración de otros materiales elaborados por los mismos estudiantes

c) La idea de usar la herramienta para el trabajo con los contenidos, en paralelo con la revisión de los elementos básicos para su utilización con los estudiantes (la cual finalmente no puede llevarse a cabo)

d) La flexibilidad en relación con las decisiones tomadas ante la falta de tiempo y el difícil acceso a los recursos tecnológicos

En este sentido, el profesor trabajó los cinco ejes de toma de decisiones contemplados en el marco de referencia al abordar las decisiones de diseño de la actividad considerando la vinculación curricular, la herramienta adecuada con la tarea y las posibilidades de los alumnos, el diseño de situaciones que lograran el involucramiento de los estudiantes, el abordaje de las dificultades y limitaciones que se fueron presentando y, por último, la consulta con colegas para retroalimentar sus decisiones a través del taller.

\subsection{Sobre el proceso de génesis instrumental}

El caso del maestro Gregorio y sus estudiantes permite analizar el uso de la tecnología a través del acercamiento instrumental (Assude et ál., 2010). Desde esta perspectiva, es posible seguir la pista de cómo el profesor organiza la actividad, cómo la presenta a sus estudiantes, y cómo el conocimiento y la percepción del profesor y sus estudiantes respecto a la herramienta tecnológica determina las decisiones que toman y los llevan a anticipar los posibles efectos de las mismas, y a construir estrategias para alcanzar cierto propósito didáctico mediante el uso de la herramienta.

Una revisión de la primera sesión en la que los alumnos manipularon y exploraron la herramienta podría interpretarse como un énfasis del profesor en el conocimiento de la herramienta y sus propiedades, es decir, en la etapa

106 I de iniciación. Sin embargo, el maestro tiene otra concepción de la relevancia 
del uso de la tecnología o de cualquier otro material como vehículo para representar los conocimientos; por ejemplo, en la entrevista, al referirse a su idea de retomar las maquetas elaboradas por sus estudiantes comentó:

Más que realizar la maqueta, es que ellos observen la diferencia entre cada uno de ellos (se refiere a los relieves geográficos). Cuando ellos lo hacen de manera mecánica recuerdan más la información.

Cuando el profesor se refiere a hacer «de manera mecánica», alude a que los alumnos aprenden cuando se relacionan con los contenidos de otra manera alternativa a la lectura de información; en este caso, con la manipulación física, con la construcción de un modelo. A partir de ello, nace su decisión de que elaboraran un video para la representación dinámica de conceptos geográficos.

Su intención no era que aprendieran la operación de la herramienta únicamente, es decir, que la experiencia se limitara al nivel de iniciación instrumental. Sin embargo, las dificultades que enfrentaron los estudiantes por su falta de familiaridad con el software llevaron al profesor a modificar la estrategia prevista. En la siguiente interacción en clase, se infiere el tipo de trabajo con las funciones específicas del software:

M: Muchachos, es exactamente lo mismo para importar imágenes, importar música. Háganlo también con las otras tareas que están ahí, con las otras actividades. Dale doble clic. [Se dirige a un alumno y le da instrucciones para abrir una carpeta en la computadora.]

A: Ahora... abrir, listo. [Abre la carpeta llamada Geografía.]

M: Entonces, bájenme imágenes, audio, están en la carpeta de Geografía [Se refiere al procedimiento para importar archivos y colocarlos en la carpeta prevista para guardar sus insumos]. ¿Vale? Entonces acuérdense que va a estar en blanco, porque no hay nada; nada más quiero que ejerciten, ¿isí?

El profesor enfatiza la ejercitación, la repetición de cadenas de instrucciones con el fin de que todos los miembros del equipo manipularan la herramienta, y esperando que -más adelante, al incorporar el contenido académico- recordarán los procedimientos. Esta situación originó que, durante las dos primeras sesiones, los alumnos se enfocaran en la manipulación de la herramienta, y perdieran de vista el propósito de la actividad, como se infiere a partir del siguiente intercambio:

A: Una pregunta. Yo no le entiendo ni lo que vamos a hacer; estoy haciendo lo que ellos me indican [dirigiéndose al maestro].

$\mathrm{M}: \mathrm{Ah}, \mathrm{OK}$, vale. Hay una parte fundamental en cuanto al hecho de que tenemos que organizarnos primero para organizar nuestras actividades 
en primera instancia. Si de alguna manera todo el equipo no entiende, entonces, también díganme para que volvamos a explicar. A partir de las imágenes, van a revisar qué tema van a trabajar, ¿estamos de acuerdo? Por ejemplo, vamos a suponer que estamos hablando de regiones naturales; bueno, vamos a observar de manera general, primero, qué son las regiones naturales; vamos a hacer nuestra presentación, nuestro título, buscar la información de qué son las regiones naturales, y posteriormente buscamos [las imágenes].

A: Aquí. [Se refiere a la carpeta Geografía donde se guardarán las imágenes.]

M: Ajá, acuérdense que ya están ahí. Y empezar a buscar la información de cómo va a ir la secuencia de su video.

A: Por decirlo, ahorita, ya escogimos esa [se refiere a una imagen del menú Transiciones de video del programa que se despliega en pantalla], ¿no? La que va a ir.

M: Sí, pero miren.

A: Despedazar dentro. [Lee de la pantalla el tipo transición seleccionada.]

[El maestro comienza a hablar, y -al mismo tiempo- va manipulando el programa; abre y cierra distintas secciones para explicarles a los alumnos]

M: OK. Pero fíjense, lo que ustedes están haciendo es generar una transición de video en este caso. ¿Se acuerdan qué explicamos, muchachos, la clase pasada? Fíjense, vamos a importar algunas imágenes para que vean ustedes nada más.

Los estudiantes están concentrados en las funciones del programa, confunden un procedimiento para manipular una imagen con la imagen en sí, puesto que todavía no cuentan con el archivo de fotografías. El profesor trata de contextualizar, dentro de la actividad, las operaciones que están realizando. En el proceso de iniciación, resulta evidente que los estudiantes tienen ciertas expectativas sobre lo que la herramienta puede hacer y cómo deben utilizarla: esto es parte del proceso de familiarizarse con ella. De la misma manera, la confusión sobre la naturaleza del proyecto se deriva del acercamiento a la herramienta que todavía no incorpora el trabajo con los contenidos académicos.

El profesor reflexionó sobre esta situación durante la entrevista; y refirió que -tras explorar la herramienta- los jóvenes se enfrentaron al problema de elegir un tema en el que tuvieran interés e información suficiente para desarrollarlo. En las primeras sesiones, no lo tenían claro: siempre habían pensado en un tema (regiones naturales) en función de las imágenes que el profesor había puesto a su disposición, pero, una vez que el manejo de la herramienta no fue obstáculo para ellos, seleccionaron el tema que les interesó, aunque no 
contaban con imágenes para armar el video. En este caso, llama la atención la flexibilidad del profesor para dar cabida a las ideas de los alumnos a pesar de lo ajustado del tiempo para finalizar el proyecto. En la entrevista final, el profesor comenta:

Yo creo que es también buscarles alternativas a los muchachos. Sobre todo, porque si en realidad el equipo, al inicio, no tenía bien identificado cómo realizar la actividad. Al equipo, se le dificultó la organización cuando teníamos lo de regiones naturales y relieves. Pero cuando entramos a las temáticas sociales, no, pues ellos manejaron de manera más clara la situación. La relacionan con una exposición que tuvieron de Español. Entonces, los muchachos dijeron: «Vamos a ubicar tres temas, tres aspectos, por ejemplo, antecedentes... el desarrollo...», me dijeron, «así como lo hicimos en Español». Entonces, se empezaron a dividir el trabajo, y creo que eso fue lo que de alguna manera les ayudó a realizar la actividad.

Puede decirse que la apropiación de la herramienta y sus características retrasó el trabajo académico. Sin embargo, una vez superada la etapa de iniciación, los alumnos pudieron transitar a la etapa de exploración; e, inclusive, a una incipiente etapa de reforzamiento. En esta última, la realización de la tarea se desplaza de los aspectos operativos de la herramienta, y se concentra en la selección de un tema relevante para ellos, la búsqueda de contenidos apropiados, su organización de acuerdo con un esquema trabajado en otra asignatura (Español) y su articulación con las imágenes para la grabación del video. Ya con cierto conocimiento de la herramienta y sus potencialidades, el maestro los apoya en el uso específico de ciertas instrucciones.

Al final del semestre, los alumnos estaban elaborando su video sobre problemáticas sociales que afectan a la población, con los siguientes subtemas: discriminación e injusticia social, hambre y marginación. Un subgrupo elaboraba el guión para su grabación, mientras que otro seleccionaba e integraba imágenes y música. Como el plan de estudios de la asignatura de Geografía es semestral, se terminaron las partes, pero la integración final del video quedó pendiente.

\section{Discusión final}

La precaria situación de trabajo del profesor Gregorio con sus estudiantes de la secundaria para trabajadores evidencia la importancia de conocer cómo se apropian de las tecnologías maestros y alumnos, cómo las insertan a sus prácticas y se benefician de su uso. El aula de esta secundaria para trabajadores se sitúa al margen de las grandes inversiones para poner a disposición de las escuelas sofisticados dispositivos tecnológicos. No obstante, es una prueba de que es en los propósitos de las actividades en las que la tecnología es utilizada, 
y cómo esos propósitos son capaces de movilizar las formas de interacción en el aula, donde hay que buscar las claves para situar la tecnología al servicio de los procesos educativos.

La experiencia con el profesor Gregorio nos acerca a una situación específica, en la que las decisiones que favorecen la exploración y experimentación de los estudiantes, y una concepción favorable de lo que pueden lograr y de cómo apoyarles pueden promover importantes -aunque sutiles-cambios en la dinámica del aula, a pesar de las limitaciones institucionales y de tiempo.

En el caso que nos ocupó, observamos cómo el profesor flexibilizó y fue adaptando las consignas y acciones planeadas de acuerdo con las necesidades de sus alumnos, con el fin de promover aprendizajes vinculados con temas relevantes para ellos, y al mismo tiempo con contenidos curriculares. Como se apuntó al inicio, la introducción de la tecnología en el aula no está determinada por procedimientos claros ni directos. Aun cuando el profesor realizó una planeación especialmente estructurada en aspectos formales y de organización, tuvo que atender problemas, como las fallas técnicas del programa, la pérdida de información, la necesidad de emplear más tiempo para la exploración de la herramienta, y la necesidad de proveer insumos, de tal manera que las decisiones le permitieran acompañar a sus estudiantes en el proceso de apropiarse del uso de la herramienta y de descubrir su potencial.

Sus expectativas sobre lo que sus estudiantes pueden lograr, su confianza en el manejo de la tecnología, la práctica informada a través del diálogo y el acompañamiento de la tutora y su deseo de experimentar y tomar riesgos son factores que configuran el desarrollo de la actividad y las decisiones que toma en el camino. Se podría apuntar que inclusive algunas de las limitaciones contribuyeron a esta postura en el docente: las condiciones de marginalidad y las bajas expectativas puestas en los estudiantes de la modalidad aparentemente liberan al profesor del estricto cumplimiento del currículo y de los tiempos institucionales.

A partir de los elementos de la perspectiva de la integración instrumental (Assude et ál., 2010), fue posible acercarse y entender cómo el profesor organiza las condiciones para la génesis instrumental de la tecnología presentada a los estudiantes. Asimismo, se pudo abordar cómo sus acciones favorecen el tránsito de las etapas de ejercitación y operación de la herramienta vacía de contenido, al trabajo y reflexión con contenidos académicos en los que la herramienta está al servicio de la actividad pedagógica. También, permiten concluir que experimentar con nuevas formas de interacción entre la tecnología, los participantes y los contenidos requiere de tiempo y voluntad.

El profesor asumió las limitantes del acceso al equipo, del tiempo disponible y de su grupo de estudiantes. Sin embargo, a la vez, se impuso el reto de diseñar una actividad que representara un desafío para él y sus alumnos. Es decir, buscaba realizar algo que supieran hacer, pero dándole un grado de dificultad tal que los condujera a crecer a partir de la experiencia de utilizar la tecnología 
Desde la etapa de diseño, el maestro enfatizó el desarrollo de una actividad concebida como vehículo de expresión para los estudiantes, y que evitara la ejercitación mecánica de procedimientos. No obstante, las limitaciones contextuales juegan un papel importante en este caso para acotar los resultados. Quizá, el video sea una forma de presentar información no muy diferente a la que se expone en una clase, pero abre la ventana a otros modos de representación del conocimiento y exploración de significados, sobre todo, para los alumnos de un contexto tan poco favorecido como el de la secundaria para trabajadores.

Las tecnologías no pueden cambiar por sí solas las prácticas de enseñanza y aprendizaje existentes de la noche a la mañana, pero sí pueden contribuir a fomentar nuevas prácticas centradas en las actividades que realizan los alumnos. La experiencia con el maestro Gregorio y sus estudiantes nos remite a la necesidad de correr riesgos y experimentar con el uso de la tecnología, a pesar de lo muy precarias que las circunstancias puedan ser. De la misma manera, interpela a la oferta de formación en el uso de la tecnología, que -por lo generalenfatiza los procedimientos y el conocimiento de la operación de herramientas. La evidencia lleva a plantearse otros modos de colaboración e intercambio de ideas entre colegas profesores, desarrolladores e investigadores en proyectos de largo aliento, con miras a trazar caminos accesibles y transitables en el proceso de inserción pedagógica de las tecnologías digitales en la escuela.

\section{Nota biográfica}

Enna Carvajal (Dra.) es Presidente del Laboratorio de Innovación en Tecnología Educativa (LITE), asociación mexicana que hace énfasis en el desarrollo de contenidos digitales educativos públicos y gratuitos, así como en la investigación de los usos y estrategias de apropiación de dichos recursos en el sistema escolar mexicano. Actualmente, ocupa la cátedra de investigación en educación y recursos digitales de Cengage Learning- Universidad Anáhuac. Ha coordinado el diseño, articulación y desarrollo de materiales educativos en formatos múltiples -impresos, digitales y audiovisuales- para la Telesecundaria, modalidad de educación media básica mexicana.

\section{Referencias}

Assude, T., Buteau, C. y Forgasz, H. (2010). Factors influencing technologyrich mathematics curriculum and practices. En Hoyles, C. y Lagrange, J. B. (Eds.), Mathematics education and technology- rethinking the terrain (405-419). Nueva York: Springer.

Area Moreira, M. (2011). Los efectos del modelo 1:1 en el cambio educativo en las escuelas. Evidencias y desafíos para las políticas iberoamericanas. Revista Iberoamericana de Educación, (56), 49-74. 
Bingimlas, K. (2009). Barriers to the successful integration of ICT in teaching and learning environments: A review of the literature. Eurasia Journal of Mathematics, Science \& Technolgy Education, 5(3), 235-245.

Canedo Castro, G. (2011). Secundarias para Trabajadores. Una posibilidad, una mirada [Publicación de Cidpae]. Recuperado de http://www.cidpae.org. $\mathrm{mx} /$ publicaciones.php

Carvajal, E. (2011). La evolución de los materiales didácticos de la Telesecundaria: Del telemaestro a la diversificación de los recursos en el aula. En Barriga, R. (Ed.), Entre paradojas: A 50 años de los libros de texto gratuitos (645-660). México, DF: El Colegio de México / Conaliteg.

Coll, C., Mauri, T. y Onrubia, J. (2008). Análisis de los usos reales de las TIC en contextos educativos formales: una aproximación sociocultural. Revista Electrónica de Investigación Educativa, 10(1), Recuperado de: http://redie. uabc.mx/index.php/redie/article/view/177

Cuban, L., Kirkpatrick, H. y Peck, C. (2001). High Access and Low Use of Technologies in High School Classrooms: Explaining an Apparent Paradox. American Educational Research Journal, 38(4), 813-834.

Del Valle, Sonia (2014). Olvida SEP capacitar en uso tecnológico. Am.com., 15 de julio de 2014. Recuperado de http://www.am.com.mx/notarefor$\mathrm{ma} / 56077$

Diario Oficial de la Federación (2013). Plan Nacional De Desarrollo 2013-2018 [Versión digital de DOF]. Recuperado de http://www.dof.gob.mx/nota detalle.php? codigo $=5299465 \&$ fecha $=20 / 05 / 2013$

Dyson, A. H. (1989). Multiple worlds of child writers. Nueva York: Teachers College Press.

Gee, J. y Green, J. (1998). Discourse analysis, learning, and social practice: A methodological study. Review of research in education, (23), 119-169. Recuperado de http://www.jstor.org/stable/10.2307/1167289

Hennessy, S., Ruthven, K. y Brindley, S. (2005). Teacher perspectives on integrating ICT into subject teaching: commitment, constrains, caution and change. Journal of Curriculum Studies, 37(2), 155-192. Recuperado de http://www.tandfonline.com/doi/abs/10.1080/0022027032000276961

Kalman, J. y Guerrero, M. E. (2013). A social practice approach to understanding teachers' learning to use technology and digital literacies in the classroom. E-Learning and Digital Media, 10(3), 260-275. Recuperado de http://dx.doi.org/10.2304/elea.2013.10.3.260

Miles, M. y Huberman, M. (1994). Qualitative data analysis: an expanded sourcebook, California: SAGE Publications.

Pelgrum, W. J. (2001). Obstacles to the integration of ICT in education: results from a worldwide educational assessment. Computers \& Education, 37(2), 163-178. 
Rojano, T. (Ed.) (2006). Enseñanza de la Física y las Matemáticas con Tecnología: Modelos de transformación de las prácticas y la interacción social en el aula. México, DF: SEP-OEI.

Ruiz Muñoz, M. M. (2011). Voces y rostros de la vida escolar en las secundarias para trabajadores. Una modalidad inclusiva. XI Congreso Nacional de Investigación Educativa. Ciudad de México, 7 al 11 de noviembre. Recuperado de http://www.comie.org.mx/congreso/memoriaelectronica/v11/ docs/area_10/0190.pdf

Severin, E., y Capota, C. (2011). Modelos Uno a Uno en América Latina y el Caribe. Panorama y perspectivas (Nota técnica IDB-TN-261 del BID, División Educación). Recuperado de http://www.iadb.org

Somekh, B. (2008). Factors affecting teachers' pedagogical adoption of ICT. Insights from Socio-Cultural Theory. International Handbook of Information Technology in Primary and Secondary Education, 20(5), 449-460.

Sutherland, R., Armstrong, V., Barnes, S., Brawn, R., Breeze, N., Gall, M. y Mattewman, S. (2004). Transforming teaching and learning: embedding ICT into every day classroom practices. Journal of Computer Assisted Learning, 20, 413-425.

Sutherland, R., Robertson, S. y John, P. (2009). Improving classroom learning with ICT. London and New York: Routledge.

Valiente, O. (2010). 1-1 in Education: Current Practice, International Comparative Research Evidence and Policy Implications. OECD Education Worling Papers, No. 44. París: OECD. Recuperado de http://dx.doi. org/10.1787/5kmjzwfl9vr2-en

Vérillon, P. y Rabardel, P. (1995). Cognition and Artefacts: A contribution to the study of thought in relation to instrumented activity. European Journal of Psychology of Education, 10(1), 77-101.

Warschauer, M. (2006). Going One-to-One. Learning in the Digital Age, 63(4), 34-38. 
